\title{
Calendar Anomalies: Before and After the Global Financial Crisis in Emerging BRIC Stock Markets
}

\author{
S. Muruganandan ${ }^{1}$, V. Santhi ${ }^{2 *}$ and Arunkumar Jayaraman ${ }^{3}$ \\ ${ }^{1}$ Assistant Professor, Department of Humanities, PSG College of Technologies, Coimbatore, Tamil Nadu, India; \\ achieveranand@gmail.com \\ ${ }^{2}$ Associate Professor and Head, Department of Humanities, PSG College of Technologies, Coimbatore, Tamil Nadu, \\ India; achieveranand@gmail.com \\ ${ }^{3}$ Final Year Student, M. Sc. Electrical Engineering and Information Technology, OVGU Magdeburg, Germany
}

\begin{abstract}
The legal and operational changes in the capital market operation of BRIC nations and availability of information at low cost and some time with no cost influenced the efficiency of capital market in the recent past. In order to identify the calendar anomalies, the present study examine the day of the week effect in the developing stock market of BRIC. The study period has been classified into three sub-periods as pre-financial crisis period (i.e., 1st January 2000 to 31st December 2007), during the financial crisis (1st January 2008 to 31st December 2009) and post financial crisis period (1st January 2010 to 31st December 2016). The dummy variable regression result evidenced that after the financial crisis period BRIC capital markets reached the efficient stage where day of the week trading rules lose the ground to earn the abnormal return. This can be attributed to recent changes in the capital market regulations and strict vigilance of the stock market watch dogs in these countries.
\end{abstract}

Keywords: Calendar Anomalies, Day-of-the-Week Effect, Dummy Variable Regression, BRIC

\section{Introduction}

Capital market efficiency theory states that the current stock price takes account of all the available information in the market. The information efficiency of the market is classified into three types as weak-form, semi-strong form and strong-form. The weak-form efficiency claims that the past price and volume data may not give significant information to predict the future price which contradicts to the technical analysts who believe that by studying the past price pattern, investors can earn excess return. Semi-strong form efficiency states that both fundamental and technical analysts cannot earn abnormal return consistently as publically available information already incorporated into the present price. On the other hand, strong-form efficiency states that current price reflects both public and private information hence even the insider cannot earn higher return than the normal profit of the company.

The presences of calendar anomalies give the significant information to the investors to earn abnormal return by understanding the past behaviors of the stock price. On the other hand, academicians can question the validity of weak-form efficient market hypothesis in the presence of calendar anomalies. Thus, the presence of calendar anomalies stands as controversial issue and attracts the academicians and researchers towards it.

\section{Review of Literature}

In finance literature, previous studies extensively examined the presences of calendar anomalies in the developed market. French ${ }^{1}$, Gibbson and Hess ${ }^{2}$ and Berument and 
Kiymaz ${ }^{3}$ documented the presence of calendar anomalies in US stock market. Heininen and Puttonen ${ }^{4}$ found significant positive return on Monday and Tuesday and negative return on Thursday and Friday in Central and Eastern European countries. Khanna and Mittal ${ }^{5}$ employed the unit root test to examine the existence and persistence of Day-of-the-Week (DOW) effect in BRICS countries and found the market inefficiency in India and China only. Aziz ${ }^{6}$ found the negative Monday effect and positive Wednesday effect for SENSEX and NIFTY respectively. However, Carluccl ${ }^{7}$ studied the USA Dow Jones index for the period of 2004 to 2012 and found no evidence of Dayof-the-Week Effect. Sing ${ }^{8}$ studied the BRIC market for the period of 2003-2010 and found the DOW effect in China and found no month of the year effect for any country. Srinivasan and Kalaivani ${ }^{9}$ studied the DOW effect for the period from 1997 to 2012 and found the positive Monday and Wednesday effect for SENSEX. Haug and Hirschey ${ }^{10}$ observed the remarkably consistent January effect in smallcap stock returns over time and not affected by passage of the Tax Reform Act of 1986. Elena and Dragos ${ }^{11}$ found the the presence of a Friday effect for Romanian Bucharest Exchange Trading - Composite Index for the period of January 2005 to December 2011 by applying the ARCH and GARCH Model by including the world market index. Sarma ${ }^{12}$ found the day-of-the-week effect in Indian Stock market for the period from January $1^{\text {st }} 1996$ to August $10^{\text {th }}$ 2002 and concluded that the traders can make consistent abnormal returns through a trading strategy of buying on Mondays and selling on Fridays.

Many empirical studies found the evidence of day-ofthe-week effect in the developed market. However, the day on which average return differs from rest of the days in a week is not the same for all the markets and further it also differs from time to time. Moreover, the legal and political changes in BRIC nations and availability of information at low cost and some time with no cost might have influenced the efficiency of the market in the recent past. In order to identify the calendar anomalies, the present study examines the day-of-the-week effect in the developing stock market of BRIC.

\section{Data and Methodology}

The daily opening and closing values of the stock market index of BRIC i.e., Brazil (BOVSPA), Russia (RTSI), India (SENSEX) and China (SHCOMP), were collected from yahoo finance for the period of seventeen years from $1^{\text {st }}$ January 2000 to $31^{\text {st }}$ December 2016 . The study period further divided into three sub-periods as pre-financial crisis period (i.e., $1^{\text {st }}$ January 2000 to $31^{\text {st }}$ December 2007), during the financial crisis ( $1^{\text {st }}$ January 2008 to $31^{\text {st }}$ December 2009 ) and post financial crisis period ( $1^{\text {st }}$ January 2010 to $31^{\text {st }}$ December 2016). This classification of the study period helps to understand whether any structural change in the calendar effect prevailed due to financial crisis.

The daily return is calculated as the percentage difference between opening price and closing price of the respective index on each day, which explained in the Equation (1) as

$$
R_{t}=\left(\frac{I_{o}-I_{c}}{I_{o}}\right) \times 100
$$

Where, $R_{t}$ is the return of the respective index on the day t. $\mathrm{I}_{0}$ and $\mathrm{I}_{\mathrm{c}}$ are opening and closing values of index on the day $t$ respectively. This study employed the dummy variable regression to test the Day-of-the-Week (DOW) effect in the selected market. To control perfect multicollinearity due to dummy variable used for each day of the week, five dummy variables have been used with no intercept as in Equation (2)

$R_{t}=\gamma_{1} D 1_{t}+\gamma_{\mathbf{2}} D 2_{t}+\gamma_{\mathbf{5}} D \mathbf{3}_{t}+\gamma_{\mathbf{4}} D \mathbf{4}_{t}+\gamma_{\mathbf{5}} D \mathbf{5}_{\tau}+\varepsilon_{\tau}$

Where, $R_{t}$ is the return of the respective index on the day t. $\mathrm{D} 1_{t}$ is a dummy variable for Monday, taking the value 1 for all Monday observations and zero otherwise, and so on, $\gamma_{1}$ to $\gamma_{5}$ represents the mean return for Monday through Friday. The error term, i.e., $\varepsilon_{t}$, is assumed to be an independent with zero mean and constant variance.

\section{Result and Discussion}

The descriptive statistics result for the daily return of BRIC stock markets is presented in Table 1. It is noticed from the mean return that except Monday all other days' average return is positive for Brazil. Wednesday and Thursday average returns were negative for Russia and China respectively. However, Indian market registered the positive average return for each day of the week during the study period. More interestingly, it is observed that the standard deviation of Monday return is the highest for all markets when comparing to other days of the week. This phenomenon clearly indicates that Monday's closing price reflects the events of three days and hence the standard deviation stands higher compared to that of other days. Moreover, Brazil (1.648), Russia (2.143) and China (1.464) exhibit the lowest standard deviation on Friday. This phenomenon indicates that Brazil, Russia and China stock markets exhibit higher volatility on Monday and remain less volatile on Friday. In spite of the highest standard deviation, Russia, India and China deliv- 
Table 1. Descriptive Statistics

\begin{tabular}{|c|c|c|c|c|c|c|}
\hline Week days & Monday & Tuesday & Wednesday & Thursday & Friday & Overall \\
\hline \multicolumn{7}{|c|}{ Brazil } \\
\hline Mean & -0.078 & 0.046 & 0.104 & 0.074 & 0.087 & 0.047 \\
\hline Median & -0.046 & 0.079 & 0.087 & 0.106 & 0.099 & 0.064 \\
\hline Std. Dev. & 1.998 & 1.777 & 1.805 & 1.851 & 1.648 & 1.820 \\
\hline Kurtosis & 5.699 & 4.380 & 3.915 & 1.311 & 2.331 & 3.780 \\
\hline Skewness & 0.430 & 0.523 & -0.539 & -0.055 & 0.101 & 0.096 \\
\hline Minimum & -9.363 & -6.627 & -11.393 & -7.337 & -6.908 & -11.39 \\
\hline Maximum & 14.656 & 13.426 & 7.611 & 7.473 & 9.566 & 14.656 \\
\hline Count & 840 & 837 & 856 & 839 & 837 & 4209 \\
\hline \multicolumn{7}{|c|}{ Russia } \\
\hline Mean & 0.053 & 0.028 & -0.051 & 0.193 & 0.108 & 0.069 \\
\hline Median & 0.176 & 0.036 & 0.041 & 0.223 & 0.127 & 0.139 \\
\hline Std. Dev. & 2.351 & 2.216 & 2.162 & 2.293 & 2.143 & 2.228 \\
\hline Kurtosis & 8.054 & 5.052 & 5.760 & 6.475 & 16.806 & 8.255 \\
\hline Skewness & -1.018 & -0.255 & -0.261 & 0.511 & 0.872 & -0.059 \\
\hline Count & 810 & 852 & 856 & 855 & 841 & 4247 \\
\hline \multicolumn{7}{|c|}{ India } \\
\hline Mean & 0.031 & 0.036 & 0.098 & 0.028 & 0.055 & 0.050 \\
\hline Median & 0.116 & 0.078 & 0.071 & 0.117 & 0.093 & 0.094 \\
\hline Std. Dev. & 1.739 & 1.436 & 1.395 & 1.394 & 1.627 & 1.524 \\
\hline Kurtosis & 14.910 & 4.293 & 2.956 & 2.486 & 4.990 & 7.844 \\
\hline Skewness & 0.503 & -0.160 & 0.039 & -0.169 & -0.348 & 0.017 \\
\hline Count & 843 & 845 & 845 & 839 & 829 & 4201 \\
\hline \multicolumn{7}{|c|}{ China } \\
\hline Mean & 0.110 & 0.010 & 0.111 & -0.114 & 0.051 & 0.034 \\
\hline Median & 0.196 & 0.139 & 0.073 & -0.079 & 0.032 & 0.065 \\
\hline Std. Dev. & 1.996 & 1.534 & 1.557 & 1.592 & 1.464 & 1.639 \\
\hline Kurtosis & 3.539 & 6.508 & 3.700 & 3.610 & 4.538 & 4.510 \\
\hline Skewness & -0.262 & -0.758 & 0.291 & -0.056 & 0.017 & -0.161 \\
\hline Count & 803 & 823 & 830 & 819 & 818 & 4093 \\
\hline
\end{tabular}

Source: Computed from secondary data

ered the positive Monday return, whereas Brazil produced negative return. It gives the opportunity to the day traders to gain from such volatility.

Panel A, B, C and D of Table 2 exhibits the dummy variable regression result for BRIC's day-of-the-week effect for the entire study period, pre-financial crisis period, during the financial crisis period and post financial crisis period respectively. Panel A reveals that the average stock return on Wednesday (0.182) and Thursday (-0.22) were significant at 5 per cent level for Brazil and China respectively. On contrary, Russia and India exhibit no significant day of the week effect for the overall study period. For pre-financial crisis period, Brazil, Russia and China have the Day-ofthe-Week effect whereas India doesn't have any day of the week effect. The average stock return on Wednesday $(0.20)$ and Friday (0.24) for Brazil, Thursday (0.34) and Friday (0.32) for Russia and Monday (0.19) and Tuesday (0.18) for China are statistically significant at 5 per cent level. India does not exhibit any difference in the daily average returns across the week during the pre-financial crisis period.

During the period of $1^{\text {st }}$ January 2008 to $31^{\text {st }}$ December 2009, Brazil, Russia and India do not show significant week day effect whereas China exhibits significantly negative Tuesday return at 5 per cent level. On contrast, post finan- 
Table 2. Days-of-the-week coefficients for BRIC

\begin{tabular}{|c|c|c|c|c|c|c|c|c|}
\hline \multirow{2}{*}{$\frac{\text { Country }}{\text { Week days }}$} & \multicolumn{2}{|c|}{ Brazil } & \multicolumn{2}{|c|}{ Russia } & \multicolumn{2}{|c|}{ India } & \multicolumn{2}{|c|}{ China } \\
\hline & Coef. & P-value & Coef. & $\mathrm{P}$-value & Coef. & P-value & Coef. & P-value \\
\hline \multicolumn{9}{|c|}{ Panel A: Overall Period } \\
\hline Monday & -0.08 & 0.21 & 0.07 & 0.39 & 0.03 & 0.55 & 0.11 & 0.06 \\
\hline Tuesday & 0.12 & 0.16 & -0.04 & 0.72 & 0.00 & 0.95 & -0.10 & 0.22 \\
\hline Wednesday & $0.18^{\star}$ & 0.04 & -0.12 & 0.28 & 0.07 & 0.37 & 0.00 & 0.99 \\
\hline Thursday & 0.15 & 0.09 & 0.13 & 0.24 & 0.00 & 0.97 & $-0.22^{\star}$ & 0.01 \\
\hline Friday & 0.17 & 0.06 & 0.04 & 0.70 & 0.02 & 0.75 & -0.06 & 0.46 \\
\hline R Square & 0.00 & & 0.00 & & 0.00 & & 0.00 & \\
\hline Adj. R Square & 0.00 & & 0.00 & & 0.00 & & 0.00 & \\
\hline \multicolumn{9}{|c|}{ Panel B: $1^{\text {st }}$ January 2000 to $31^{\text {st }}$ December 2007} \\
\hline Monday & -0.12 & 0.18 & 0.09 & 0.42 & 0.03 & 0.68 & $0.19^{*}$ & 0.02 \\
\hline Tuesday & 0.07 & 0.47 & 0.07 & 0.55 & 0.09 & 0.22 & $0.18^{*}$ & 0.02 \\
\hline Wednesday & $0.20^{*}$ & 0.03 & -0.12 & 0.29 & 0.11 & 0.17 & 0.11 & 0.16 \\
\hline Thursday & 0.03 & 0.77 & $0.34^{*}$ & 0.00 & 0.10 & 0.19 & -0.08 & 0.29 \\
\hline Friday & $0.24^{*}$ & 0.01 & $0.32^{*}$ & 0.00 & 0.06 & 0.44 & 0.02 & 0.79 \\
\hline R Square & 0.01 & & 0.01 & & 0.00 & & 0.01 & \\
\hline Adj. R Square & 0.01 & & 0.01 & & 0.00 & & 0.01 & \\
\hline \multicolumn{9}{|c|}{ Panel C: $1^{\text {st }}$ January 2008 to $31^{\text {st }}$ December 2009} \\
\hline Monday & -0.03 & 0.90 & 0.06 & 0.88 & -0.04 & 0.87 & 0.13 & 0.60 \\
\hline Tuesday & 0.26 & 0.35 & -0.05 & 0.89 & -0.06 & 0.81 & $-0.65^{\star}$ & 0.01 \\
\hline Wednesday & -0.15 & 0.59 & -0.29 & 0.42 & 0.17 & 0.50 & 0.24 & 0.32 \\
\hline Thursday & 0.23 & 0.40 & 0.18 & 0.61 & -0.23 & 0.39 & -0.02 & 0.94 \\
\hline Friday & -0.05 & 0.87 & -0.06 & 0.88 & 0.16 & 0.55 & -0.03 & 0.91 \\
\hline R Square & 0.00 & & 0.00 & & 0.00 & & 0.02 & \\
\hline Adj. R Square & -0.01 & & -0.01 & & -0.01 & & 0.01 & \\
\hline \multicolumn{9}{|c|}{ Panel D: $1^{\text {st }}$ January 2010 to $31^{\text {st }}$ December 2016} \\
\hline Monday & -0.04 & 0.61 & -0.08 & 0.46 & 0.05 & 0.36 & 0.01 & 0.87 \\
\hline Tuesday & -0.04 & 0.61 & 0.00 & 0.98 & 0.00 & 0.96 & 0.02 & 0.85 \\
\hline Wednesday & 0.07 & 0.40 & 0.10 & 0.30 & 0.07 & 0.23 & 0.08 & 0.33 \\
\hline Thursday & 0.08 & 0.29 & 0.08 & 0.45 & 0.01 & 0.81 & -0.18 & 0.03 \\
\hline Friday & -0.05 & 0.50 & -0.10 & 0.34 & 0.02 & 0.71 & 0.11 & 0.18 \\
\hline R Square & 0.00 & & 0.00 & & 0.00 & & 0.00 & \\
\hline Adj. R Square & 0.00 & & 0.00 & & 0.00 & & 0.00 & \\
\hline
\end{tabular}

Source: Computed from secondary data

cial crisis period from 1st January 2010 to 31st December 2016, all the BRIC markets show no difference in the daily returns across the week. This result confirms that, in the later stage of the study period, the selected stock markets reached the efficient stage, where day-of-the-week trading rules lose the ground to earn the abnormal return. This may be due to changes in the rules and regulations and the extensive reach of internet in these nations making the information available at high speed with low cost.

\section{Key Findings}

- Brazil (1.648), Russia (2.143) and China (1.464) exhibit the lowest standard deviation on Friday, hence indicates that Brazil, Russia and China stock markets exhibit higher volatility on Monday and remain less volatile on Friday.

- In spite of the highest standard deviation, Russia, India and China delivered the positive Monday return, whereas Brazil produced negative return. It gives the opportunity to the day traders to gain from such volatility. 
- During the period of $1^{\text {st }}$ January 2008 to $31^{\text {st }}$ December 2009, Brazil, Russia and India do not show significant week day effect whereas China exhibits significantly negative Tuesday return at 5 per cent level.

- In the post financial crisis period from 1st January 2010 to 31st December 2016, all the BRIC markets show no difference in the daily returns across the week, and this confirms that, in the later stage of the study period, the selected stock markets reached the efficient stage, where day-of-the-week trading rules lose the ground to earn the abnormal return. This can be attributed to changes in the rules and regulations and the extensive reach of internet in these nations making the information available at high speed with low cost.

\section{Conclusion}

Emerging markets become the favored investment avenue for the international equity investors. Specifically, BRIC draw the attention of foreign equity investment by accelerating regulatory reforms and removal of other barriers for the international equity investments. However, the question of market efficiency attracts the academicians and investors to find the answer for it. Earlier research found the calendar anomalies in the developing market. The result of the study confirm the day of the week effect before the financial crisis period. However, the day of the week day evidence disappears in the recent past in all the BRIC nations. This may be due to regularity and legal changes in the BRIC capital market operations in the recent past and more specifically after the financial crisis. In addition, extensive reach of internet in these nations made the information available at high speed with low cost and some time with no cost remove the inefficiency of the day of the week effect in BRIC markets.

\section{Reference}

1. French. Stock returns and the weekend effect. Journal of Financial Economics.1980; 8(1):55-69. https://doi.org/10.1016/0304-405X(80)90021-5
2. Gibbson, Hess. Day of the week effects and asset returns. Journal of Business.1981; 54(4):579-98. https://doi.org/10.1086/296147

3. Berument, Kiymaz. The day of the week effect on stock market volatility. Journal of Economics and Finance. 2001; 25(2):181-93. https://doi.org/10.1007/BF02744521

4. Heininen, Puttonen. Stock market efficiency in the transition economies through lence of calendar anamolies. Available from: from http://www.hse.ru/data/090/182/1235/Heininen_Puttonen_ paper.pdf

5. Khanna V, Mittal A. Does day-of-the-week anomaly influence BRICS stock markets? A Unit Root Testing Approach. Journal of Business. 2016; 5(1):9-17.

6. Aziz T. Day of the week effect: Evidence from India. Afro-Asian Journal of Finance and Accounting. 2013; 5(2):99-112. https://doi.org/10.1504/AAJFA.2015. 069886

7. Carlucd F. The week day effect anomaly in the behaviour of stock index returns of Brazil, Mexico and the U.S.A. Business and Management Review. 2014; 3(9):31-8.

8. Sing S. Stock market anomalies: Evidence from emerging BRIC Market. Vision, Journal of Business Perspective. 2014; 18(1):23-8. https://doi.org/10.1177/0972262913517329

9. Srinivasan P, Kalaivani M. DOW effects in the Indian Stock Market. International Journal of Economics and Management. 2014; 8(1):158-77.

10. Haug M, Hirschey M. The January effect. Financial Analysts Journal. 2006; 62(5):78-88. https://doi.org/10.2469/faj.v62.n5.4284

11. Elena V, Dragos O. Seasonality in the Romanian stock market: The-day-of-the-week effect. Procedia Economics and Finance. 2014; 15:704-10. https://doi.org/10.1016/S2212-5671(14)00543-7

12. Sarma, S. Stock market seasonality in emerging market. Vikalpa. 2004; 29(3):35-41. https://doi.org/10.1177/0256090920040303

13. Brooks, Persand. Seasonality in Southeast Asian stock markets: Some new evidence on day- of-the-week effects. Applied Economics Letters. 2001; 8(3):155-8. https://doi.org/10.1080/13504850150504504 